Original article

\title{
Prevalence of metabolic syndrome and its components among a population- based study in south of Iran, PERSIAN Kharameh cohort study
}

\author{
Hossein-Ali Nikbakht ${ }^{\mathrm{a}, \mathrm{b}}$, Abbas Rezaianzadeh ${ }^{\mathrm{c}}$, Mozhgan Seif ${ }^{\mathrm{d}}$, Haleh Ghaem ${ }^{\mathrm{e}, *}$ \\ ${ }^{\text {a }}$ Student Research Committee, Shiraz University of Medical Sciences, Shiraz, Iran \\ ${ }^{\mathrm{b}}$ Social Determinants of Health Research Center, Health Research Institute, Babol University of Medical Sciences, Babol, Iran \\ ${ }^{c}$ Colorectal Research Center, Shiraz University of Medical Sciences, Shiraz, Iran \\ ${ }^{\mathrm{d}}$ Department of Epidemiology, School of Health, Shiraz University of Medical Sciences, Shiraz, Iran \\ ${ }^{\mathrm{e}}$ Non-communicable Diseases Research Center, Department of Epidemiology, School of Health, Shiraz University of Medical Sciences, Shiraz, Iran
}

\section{A R T I C L E I N F O}

\section{Keywords:}

Prevalence

Metabolic syndrome

Cohort studies

Iran

\begin{abstract}
A B S T R A C T
Objectives: over the past few years, lifestyle modification has increased the prevalence of major components of metabolic syndrome (MetS), leading to increased risk of non-communicable diseases, especially cardiovascular disease. The present study was aimed to determine the prevalence of MetS and its components and present results according to the major demographic characteristics of the participants in a population-based study.

Methods: This cross-sectional study was conducted on a total of 10663 subjects aged 40-70 years who participated in phase one of PERSIAN Kharameh cohort carried out between 2014 and 2017.

Result: According to IDF, ATP III, and an Iranian definition, the prevalence of MetS were reported as 37.00\%(36.08-37.92), 33.82\% (32.93-34.73), and 33.13\% (32.24-34.03), respectively. The most prevalent component of MetS was abdominal obesity (73.59), followed by reduced HDL cholesterol levels (44.83), elevated triglyceride (28.3), fasting glucose (35.34), and high blood pressure (32.64). In addition, the prevalence of MetS were 50.3, 70.4, 68.2, 65.7, and 60.8 among individuals with abdominal obesity, high triglyceride levels, hypertension, impaired fasting glucose, and low HDL-C levels, respectively. Results showed that $90 \%$ of the subjects displayed at least one component of MetS, and all MetS components were associated with major demographic characteristics of the study subjects.

Conclusions: The findings of this study indicate high prevalence of metabolic risk factors among study population. This study with a large sample size would contribute to establishment of efficient interventions and programs aimed at reducing the prevalence of MetS by health staff, supervisors and policymakers.
\end{abstract}

\section{Introduction}

In recent decades, rapid socioeconomic growth caused changes in lifestyle patterns in modern societies, which has led to the development of key components of the metabolic syndrome (MetS). ${ }^{1}$ MetS is defined by a cluster of risk factors such as abdominal obesity, insulin resistance, dyslipidemia and hypertension that increase the risk of diseases, such as type 2 diabetes mellitus, cardiovascular disease, cancer and premature death. ${ }^{2}$ These medical conditions are major health problems throughout the world. MetS is associated with a twofold increase in cardiovascular diseases, and fivefold increase in risk of diabetes, thus this condition can be effectively used for CVD risk assessment. ${ }^{3}$ Middle-aged individuals with MetS are two times more likely to develop CVD over the coming decades of their life. ${ }^{4}$ The prevalence of MetS has shown an increasing trend over time, and increasing to epidemic proportions at present. $^{5}$ It is estimated that $20-25 \%$ of the adult population suffers from MetS worldwide. ${ }^{6}$ A systematic review study conducted on Iranian population older than 19 years, reviewed 43 related studies and reported the prevalence of MetS as $10-60 \%$ depending on gender, age, and region. ${ }^{7}$ The prevalence of MetS varies widely worldwide, especially in Asian countries, due to large differences in lifestyle and variety of ethnic groups. ${ }^{8}$

Co-occurrence of all components of MetS, increase the risk of CVDs and CVD-related consequences, including morbidity and mortality, which is beyond what is expected from a single component. ${ }^{9,10} \mathrm{Al}-$ though, metabolic components are likely to overlap, ${ }^{11}$ most longitudinal studies have shown that abdominal obesity is an independent predictor of new onset of individual components of MetS. ${ }^{12}$ Increased obesity to epidemic proportions, is associated with increased MetS to epidemic proportions in that community. ${ }^{13}$ Obesity, is not always

\footnotetext{
* Corresponding author. Department of Epidemiology, School of Health, Shiraz University of Medical Sciences, Shiraz, Iran.

E-mail addresses: ghaemh@sums.ac.ir, ghaemh@sums.ac.ir (H. Ghaem).
} 
synonymous with MetS, but it may negatively affect diagnostic criteria for MetS, including waist circumference (WC), blood pressure, triglyceride levels, fasting glucose levels, and HDL cholesterol levels. ${ }^{14,15}$ Previous studies have shown that MetS is associated with several factors. For example, Xi and colleagues reported female gender, older age, overweight, obesity, and urbanization as predictors of MetS. ${ }^{16}$ In a study conducted in Iran, variables such as female gender, older age, and low educational level were associated with increased risk of MetS. ${ }^{17}$ Thus, the literature review indicates that MetS is a multifactorial disorder.

Extraction of data on chronic diseases and associated risk factors is essential for healthcare planning in all types of communities. The majority of population-based studies with large sample size on MetS have been conducted in rich countries. Due to lifestyle variations and the specific lifestyles of each region, studies should be carried out in different regions of the world. Therefore, the present study was aimed to determine the prevalence of MetS and its components, and provide results according to the major demographic characteristics of a sample of 10,663 populations in a population-based and cohort design.

\section{Materials and methods}

\subsection{Introduction of this study and Kharameh PERSIAN cohort}

This population-based cross-sectional study extracted the required data from phase 1 Persian cohort study conducted in Kharameh County. Kharameh cohort is a part of a large Persian cohort study, Prospective Epidemiological Research Studies in Iran (PERSIAN). This cohort study was designed and conducted in 2014, and comprised of different geographical, ethnical and climatic groups in 18 provinces of Iran. ${ }^{18}$ One of these provinces was Fars province. Kharameh County is located in Fars province, southern Iran with 54864 populations and the main ethnic group in the County is Fars (Appendix 2).

\subsection{Study population}

This study enrolled a total of 10663 people, aged 40-70 years who participated in first phase of Kharameh cohort conducted between 2014 and 2017. The required data were extracted from PERSIAN cohort study, in which data collection procedure constituted of registration, laboratory sample collection, obtaining anthropometric characteristics of the subjects, and questionnaire completion by study subjects. All study interviewers were selected among local residents with related collage education through qualification interview, and were provided by required practical training in a number of workshops. The main inclusion criteria were 40-70 years of age, living in Kharameh County, and Iranian nationality. The exclusion criteria were: lack of presence in clinics for physical examination, mental retardation, and unwillingness to participate into the study. All questionnaires were completed by using online survey through dedicated platform.

\subsection{Clinical and demographic data}

The collected data included demographic, anthropometric, blood pressure measurements, and biochemical parameters. Questions on demographic Characteristics included age, gender, area of living, marital status, current education and job. Anthropometric indicators also included weight $(\mathrm{kg})$, height and WC $(\mathrm{cm})$. For body mass index, participants were divided into the following groups: low weight $(\mathrm{BMI}<18.5 \mathrm{~kg} / \mathrm{m} 2)$, normal weight $($ BMI $=18.5-24.99 \mathrm{~kg} / \mathrm{m} 2)$, overweight (BMI $=25-29.9 \mathrm{~kg} / \mathrm{m} 2$ ), and Obesity (BMI $\geq 30 \mathrm{~kg} / \mathrm{m} 2$ ). Also, the following blood biochemical parameters were used as components of the MetS: fasting plasma glucose (FPG), triglycerides (TG), and high density lipoprotein cholesterol (HDL-C). Blood pressure was measured two times with 15-m interval and two measures were finally recorded for each subject.

\subsection{Definition of metabolic syndrome}

The prevalence of MetS is provided by three different definitions, Iranian definition, ${ }^{19}$ International Diabetes Federation (IDF) definition, ${ }^{20}$ and Adult Treatment Panel (ATP III) definition. ${ }^{6}$ However, the IDF definition was selected to determine the prevalence of MetS Components. According to the National Cholesterol Education program ATP III (NCEP-ATP III) criteria and Iranian definition, patients were classified as having MetS if they had three or more of the five CVD risk factors. However, international diabetes federation has introduced other diagnostic criteria for MetS to highlight the significantl role of abdominal obesity in MetS. According to IDF criteria, patients were classified as having MetS if they had abdominal obesity plus two of other MetS components.

Obesity is the first component of MetS, which is reported differently in ATP III, IDF, and Iranian definitions. As such, abdominal obesity is shown as WC $\geq 95 \mathrm{~cm}$ in both males and females in Iranian definition, WC $\geq 102 \mathrm{~cm}$ in males and $\geq 88 \mathrm{~cm}$ in females in ATP III definition, and WC $\geq 94 \mathrm{~cm}$ in males and $\geq 80 \mathrm{~cm}$ in females in IDF definition. Elevated triglyceride is another component of MetS ( $\geq 150 \mathrm{mg} / \mathrm{dl})$. In addition, reduced HDL-C is another frequent component of MetS ( $<40 \mathrm{mg} / \mathrm{dl}$ in males vs. $<50 \mathrm{mg} / \mathrm{dl}$ in females). Another component of MetS is elevated blood pressure (Systolic BP $\geq 130 \mathrm{mmHg}$ and diastolic BP $\geq 85 \mathrm{mmHg}$ ) or treatment of previously diagnosed elevated blood pressure. Finally, fasting glucose ( $\geq 100 \mathrm{mg} / \mathrm{dl}$ ) or previous detection of type 2 diabetes.

\subsection{Statistical analysis}

The descriptive data were expressed as mean \pm standard deviation, and frequency (percentage). The prevalence of MetS and its components were computed with $95 \%$ confidence interval. Also, chisquare test was used to assess statistically significant relationship between qualitative variables. Data analysis was performed using Stata, version 11.0 for Windows (Stata Corp., College Station, TX, USA). the significance level was set at $<0.05$.

\subsection{Ethical issues}

Prior to conducting the study, ethics committee confirmation were taken from Shiraz University of Medical Sciences (ethical code: IR.SUMS.REC.1398.445). Confidentiality of their personal data was emphasized.

\section{Result}

The mean age of the participants was $51.948 \pm 8.27$ years. Of the 10663 participants in the Kharameh cohort study, 4719 cases were males (44.3\%) and 4416 cases were living in rural areas (41.4\%), \%, 9492 cases (89\%) were married, and 5587 (52.4\%) were illiterate. (Demographic characteristics are presented in Table 1).

The IDF, ATP III, and an Iranian definition, reported the prevalence of MetS as 37.00 (36.08-37.92), 33.82 (32.93-34.73), and 33.13 (32.24-34.03), respectively (appendix 1). All results and analyses were obtained using IDF criteria. The most prevalent component of MetS was abdominal obesity (73.59), followed by reduced HDL cholesterol levels (44.83), fasting glucose (35.34), and high blood pressure (32.64), elevated triglyceride (28.33) (Table 2).

The findings of our study indicate that demographic characteristics of the subjects were associated with MetS $(\mathrm{p}<.05)$. Accordingly, the risk of MetS is increased by each decade of life, as the prevalence of MetS is $31.8 \%$ in subjects younger than 50 years and $45.9 \%$ in subjects aged 60-70 years. Also, MetS is two times more prevalent among female patients $(50.2 \%)$ than males. The MetS was shown to be more prevalent in subjects living in urban areas compared to those living in rural areas, but the difference was not magnificent, as the prevalence of 
Table 1

Demographic characteristics of subjects in Kharameh cohort by presence of MetS according to IDF definition ( $\mathrm{n}=10663$ ).

\begin{tabular}{|c|c|c|c|c|c|}
\hline \multirow[t]{2}{*}{ Variable } & \multirow[t]{2}{*}{ Subgroup } & \multirow{2}{*}{$\begin{array}{l}(\%) N \\
(n=10663)\end{array}$} & \multicolumn{2}{|c|}{ Metabolic Syndrome } & \multirow[t]{2}{*}{ p-value } \\
\hline & & & $\begin{array}{l}\text { Yes }(\%) \mathrm{N} \\
(\mathrm{n}=3946)\end{array}$ & $\begin{array}{l}\text { No }(\%) \mathrm{N} \\
(\mathrm{n}=6717)\end{array}$ & \\
\hline \multirow[t]{3}{*}{ Age group (years) } & $40-49$ & $4686(43.9)$ & $1490(31.8)$ & $3196(68.2)$ & \multirow[t]{3}{*}{$<0.001$} \\
\hline & $50-59$ & $3759(35.3)$ & $1439(38.3)$ & $2320(61.7)$ & \\
\hline & $60-69$ & $2218(20.8)$ & $1017(45.9)$ & $1201(54.1)$ & \\
\hline \multirow[t]{2}{*}{ Sex } & Male & $4719(44.3)$ & $962(20.4)$ & $3757(79.6)$ & \multirow[t]{2}{*}{$<0.001$} \\
\hline & Female & $5944(55.7)$ & $2984(50.2)$ & $2960(49.8)$ & \\
\hline \multirow[t]{2}{*}{ Place of residence } & Urban & $4416(41.4)$ & $1697(38.4)$ & $2719(61.6)$ & \multirow[t]{2}{*}{0.011} \\
\hline & Rural & $6247(58.6)$ & $2249(36.0)$ & $3998(64.0)$ & \\
\hline \multirow[t]{2}{*}{ Marital status } & Married & $9492(89.0)$ & $3301(34.8)$ & $6191(65.2)$ & \multirow[t]{2}{*}{$<0.001$} \\
\hline & Single & $1171(11.0)$ & $645(55.1)$ & $526(44.9)$ & \\
\hline \multirow[t]{2}{*}{ Education } & Illiterate & $5587(52.4)$ & $2370(42.4)$ & $3217(57.6)$ & \multirow[t]{2}{*}{$<0.001$} \\
\hline & Literate & $5076(47.6)$ & $1576(31.0)$ & $3500(69.0)$ & \\
\hline \multirow[t]{2}{*}{ Job } & Employed & $5516(51.7)$ & $1356(24.6)$ & $4160(75.4)$ & \multirow[t]{2}{*}{$<0.001$} \\
\hline & Unemployed & $5147(48.3)$ & $2590(50.3)$ & $2557(49.7)$ & \\
\hline \multirow[t]{4}{*}{ Body Mass Index (kg/m2) (BMI) } & Low weight & $411(3.9)$ & $9(2.2)$ & $402(97.8)$ & \multirow[t]{4}{*}{$<0.001$} \\
\hline & Normal & $3882(36.4)$ & 764(19.7) & $3118(80.3)$ & \\
\hline & Overweight & $4451(41.7)$ & $2033(45.7)$ & $2418(54.3)$ & \\
\hline & Obese & 1919(18.0) & $1140(59.4)$ & $779(40.6)$ & \\
\hline
\end{tabular}

MetS was 38.4 and 36.0 among subjects living in urban and rural areas, respectively. Results also showed that single, illiterate and employed individuals are more likely to develop MetS. Furthermore, the prevalence of MetS was 45.7 in overweight, and 59.4 in obese patients (Table 1).

According to IDF criteria, abdominal obesity is defined as WC, thus those with no abdominal obesity displayed no MetS, and $50.3 \%$ of those with abdominal obesity reported MetS. Also, the prevalence of MetS was $70.4 \%$ in subjects with elevated triglyceride, whereas $23.8 \%$ of those with normal triglyceride levels displayed MetS. In addition, the prevalence of MetS among those with high blood pressure, impaired fasting glucose, and low HDL-C levels were 68.2, 65.7, and 60.8, respectively (Table 2).

Analysis of the relationship between MetS components and demographic characteristics revealed that MetS components were most prevalent in patients with abdominal obesity by age, as $77.81 \%$ of subjects aged 60 years and older displayed MetS components. Also, MetS components were least frequent in patients with high blood pressure, as $24.34 \%$ of subjects with high blood pressure reported MetS components in subjects younger than 50 years. Moreover, the frequency of components of MetS were shown to increase with age. However, reduced HDL-C decreased, and elevated triglyceride was stable with age.

Beides, all five MetS components were more prevalent among females, that is more than $90 \%$ of female subjects reported abdominal obesity. All MetS components were significantly different between male and female patients, with no significant difference in elevated triglyceride $(\mathrm{p}<.001)$.
The prevalence of high blood pressure, abdominal obesity and impaired fasting glucose were significantly higher in illiterate subjects ( $\mathrm{p}<.001$ ). also, the prevalence of all MetS components were significantly higher in single and unemployed subjects $(\mathrm{p}<.001)$. those living in urban areas were more likely to display most of significant MetS components than those living in rural areas (Table 3).

Results showed that $90 \%$ of the subjects displayed at least one component of MetS (80\% in males vs. $97 \%$ in females). Besides, $1.27 \%$ of male patients and $5.33 \%$ of female patients reported having all five components of MetS. In most cases, the highest prevalence of MetS was observed in subjects who had two or three MetS components (almost one third of the total study population). The frequency of MetS components by demographic characteristics are presented in Table 4.

\section{Discussion}

The present study determined the prevalence of MetS and its individual components by demographic characteristics. The prevalence of MetS was reported $37 \%$ by IDF definition, which was higher than other definitions. Also, the most frequent MetS component was abdominal obesity $(73.59 \%)$, and the most prevalent MetS component among subjects with MetS was elevated triglyceride (70.4\%). Besides, $90 \%$ of the subjects displayed at least one component of MetS. All five components of MetS were associated with major demographic characteristics.

The prevalence of MetS by IDF and ATP III were $37 \%$ and $33.82 \%$, respectively. The prevalence of MetS varies widely throughout the

Table 2

Prevalence of MetS components in Kharameh cohort participants by presence of MetS according to IDF definition (n = 10663).

\begin{tabular}{|c|c|c|c|c|c|}
\hline \multirow[t]{2}{*}{ Variable } & \multirow[t]{2}{*}{ Subgroup } & \multirow{2}{*}{$\begin{array}{l}(\%) \mathrm{N} \\
(\mathrm{n}=10663)\end{array}$} & \multicolumn{2}{|c|}{ Metabolic Syndrome } & \multirow[t]{2}{*}{ p-value } \\
\hline & & & $\begin{array}{l}\text { Yes }(\%) \mathrm{N} \\
(\mathrm{n}=3946)\end{array}$ & $\begin{array}{l}\text { No }(\%) \mathrm{N} \\
(\mathrm{n}=6717)\end{array}$ & \\
\hline \multirow[t]{2}{*}{ Central obesity } & Ok & $7847(73.6)$ & $3946(50.3)$ & 3901(49.7) & \multirow[t]{2}{*}{$<0.001$} \\
\hline & No & $2816(26.4)$ & 0 & $2816(100)$ & \\
\hline \multirow[t]{2}{*}{ Raised fasting blood sugar } & Ok & $3769(35.3)$ & $2477(65.7)$ & $1469(34.3)$ & \multirow[t]{2}{*}{$<0.001$} \\
\hline & No & $6894(64.7)$ & $1292(21.3)$ & $5425(78.7)$ & \\
\hline \multirow[t]{2}{*}{ Raised TG level } & Ok & $3021(28.3)$ & $2126(70.4)$ & $895(29.6)$ & \multirow[t]{2}{*}{$<0.001$} \\
\hline & No & $7642(71.7)$ & $1820(23.8)$ & $5822(76.2)$ & \\
\hline \multirow{2}{*}{ Reduced HDL cholesterol } & Ok & $4781(44.8)$ & $29.6(60.8)$ & $1875(39.2)$ & \multirow[t]{2}{*}{$<0.001$} \\
\hline & No & $5882(55.2)$ & $1040(17.7)$ & $4842(82.3)$ & \\
\hline \multirow[t]{2}{*}{ Raised blood pressure } & Ok & $3481(32.6)$ & $2373(68.2)$ & $1108(31.8)$ & \multirow[t]{2}{*}{$<0.001$} \\
\hline & No & $7182(67.4)$ & $1573(21.9)$ & $56.9(78.1)$ & \\
\hline
\end{tabular}


Table 3

Prevalence of MetS components by demographic characteristics according to IDF Definition ( $\mathrm{n}=10663$ ).

\begin{tabular}{|c|c|c|c|c|c|c|c|}
\hline Variable & Subgroup & Metabolic Syndrome & Central obesity & Raised FBS & Raised TG level & Reduced HDL cholesterol & Raised blood pressure \\
\hline \multirow[t]{4}{*}{ Age group (years) } & $40-49$ & $31.79(30.47-33.14)$ & $71.08(69.76-72.36)$ & $26.61(25.36-27.89)$ & $27.40(26.14-28.69)$ & $47.20(45.77-48.63)$ & $24.34(23.14-25.59)$ \\
\hline & $50-59$ & $38.28(36.73-39.84)$ & $74.22(72.79-75.59)$ & $39.15(37.61-40.73)$ & $30.08(28.64-31.57)$ & $43.30(41.73-44.90)$ & $34.95(33.44-36.49)$ \\
\hline & $60-69$ & $45.85(43.78-47.93)$ & 77.81(76.04-79.49) & $47.33(45.26-49.42)$ & $27.32(25.50-29.21)$ & $42.42(40.38-44.49)$ & $46.25(44.18-48.33)$ \\
\hline & $\mathrm{P}$-value & $<0.001$ & $<0.001$ & $<0.001$ & 0.012 & $<0.001$ & $<0.001$ \\
\hline \multirow[t]{3}{*}{ Sex } & Male & $20.38(19.26-21.55)$ & $49.18(47.75-50.61)$ & $31.00(29.69-32.33)$ & $27.76(26.50-29.05)$ & $28.71(27.44-30.02)$ & $25.34(24.12-26.60)$ \\
\hline & Female & $50.20(48.93-51.47)$ & $92.96(92.28-93.59)$ & $38.79(37.56-40.04)$ & $28.78(27.64-29.95)$ & $57.63(56.37-58.88)$ & $38.44(37.21-39.68)$ \\
\hline & P-value & $<0.001$ & $<0.001$ & $<0.001$ & 0.243 & $<0.001$ & $<0.001$ \\
\hline \multirow[t]{3}{*}{ Place of residence } & Urban & $38.42(37.00-39.87)$ & 76.17(74.89-77.41) & $35.52(34.13-36.95)$ & $31.79(30.43-33.18)$ & $45.99(44.52-47.46)$ & $31.74(30.39-33.13)$ \\
\hline & Rural & $36.00(34.81-37.20)$ & $71.76(70.63-72.86)$ & $35.21(34.04-36.41)$ & $25.88(24.81-26.98)$ & $44.02(42.79-45.25)$ & $33.27(32.12-34.45)$ \\
\hline & $\mathrm{P}$-value & 0.011 & $<0.001$ & 0.739 & $<0.001$ & 0.044 & 0.097 \\
\hline \multirow[t]{3}{*}{ Marital status } & Single & $55.08(52.21-57.91)$ & $89.49(87.60-91.12)$ & $46.45(43.61-49.32)$ & $31.25(28.66-33.97)$ & $54.14(51.27-56.98)$ & $47.39(44.54-50.26)$ \\
\hline & Married & $34.77(33.82-35.74)$ & $71.62(70.71-72.52)$ & $33.97(33.02-34.93)$ & $27.97(27.07-28.88)$ & $43.68(42.69-44.68)$ & $30.82(29.90-31.76)$ \\
\hline & P-value & $<0.001$ & $<0.001$ & $<0.001$ & 0.019 & $<0.001$ & $<0.001$ \\
\hline \multirow[t]{3}{*}{ Education } & Illiterate & $42.41(41.12-43.72)$ & $77.17(76.05-78.26)$ & $40.18(38.90-41.47)$ & $27.72(26.56-28.91)$ & $45.53(44.23-46.84)$ & $41.04(39.75-42.33)$ \\
\hline & Literate & $31.04(29.78-32.33)$ & $69.64(68.36-70.89)$ & $30.02(28.77-31.29)$ & $28.99(27.76-30.26)$ & $44.07(42.70-45.44)$ & $23.40(22.25-24.58)$ \\
\hline & $\mathrm{P}$-value & $<0.001$ & $<0.001$ & $<0.001$ & 0.145 & 0.129 & $<0.001$ \\
\hline \multirow[t]{3}{*}{ Job } & Unemployed & $50.32(48.95-51.68)$ & $88.90(88.01-89.73)$ & $41.36(40.02-42.71)$ & $30.56(29.31-31.83)$ & $54.07(52.70-55.42)$ & $41.48(40.14-42.83)$ \\
\hline & Employed & $24.58(23.46-25.73)$ & $59.30(57.99-60.59)$ & $29.73(28.53-30.95)$ & $26.25(25.10-27.42)$ & $36.22(34.96-37.49)$ & $24.40(23.28-25.55)$ \\
\hline & P-value & $<0.001$ & $<0.001$ & $<0.001$ & $<0.001$ & $<0.001$ & $<0.001$ \\
\hline Total & & $37.00(36.08-37.92)$ & $73.59(72.75-74.42)$ & $35.34(34.43-36.25)$ & $28.33(27.41-29.18)$ & $44.83(43.89-45.78)$ & $32.64(31.75-33.53)$ \\
\hline
\end{tabular}

world, as it was reported as $34.1 \%$ among American adults aged older than 20 years, ${ }^{21} 21.5 \%$ in france, ${ }^{22} 33.5 \%$ in turkey, ${ }^{23} 54.8 \%$ in Mexico City, ${ }^{24} 36.4$ in Taiwan ${ }^{25}$ and Korea, ${ }^{26}$ and $23 \%$ in Sweden. ${ }^{27}$ Delavari and colleagues conducted a national study in Iran, and reported the prevalence of MetS as $34.7 \%$ by ATP III definition, and $37.4 \%$ by IDF definition. ${ }^{28}$ Also, Mokhayeri and colleagues reported the prevalence of MetS as $28 \%,{ }^{29}$ while Hajian and colleagues reported the prevalence of MetS as $42.3 \%$, ${ }^{17}$ which was significantly higher than other studies and was supported by Iranian national study. the estimation of the prevalence of MetS depends on the applied diagnostic definition, time of study, age, gender, and ethnicity of the population. ${ }^{30}$ Differences between assessment criteria make it difficult to accurately compare interpopulation differences. Besides, in populations with lower prevalence of obesity, the estimation of MetS by IDF and ATP III definitions would be similar. ${ }^{31}$ Therefore, due to these contradicting definitions, comparison of different study results should be done with great caution.

The most prevalent component of MetS was abdominal obesity (73.59), followed by reduced HDL-C levels (44.83), fasting glucose (35.34), high blood pressure (32.64), and elevated triglyceride (28.33). a study conducted in southern Iran reported the prevalence of components of MetS were as follows: $29.4 \%$ for abdominal obesity, $40.2 \%$ for elevated triglyceride, $40.2 \%$ for reduced HDL-C, $15.4 \%$ for hypertension, and $37.8 \%$ for high fasting glucose. ${ }^{32}$ Ryu and colleagues reported that the most prevalent components of MetS were high WC (27.5\%), elevated glucose levels (23.1\%), elevated triglyceride (22.2\%), reduced HDL-C (13.4\%), and high blood pressure $(9.4 \%),{ }^{33}$ which were not supported by results of our study.

The findings of our study demonstrated higher prevalence of obesity among females, which was supported by results of previous studies. Mirzazadeh and colleagues performed a systematic review and metaanalysis, and indicated that women are two times more likely than men to develop obesity. ${ }^{34}$ Cuschieri and colleagues conducted a study in Malta and revealed that men displayed higher rate of abdominal obesity, because waist circumference was significantly higher in men than in women in this region of the world. ${ }^{35}$ In fact, WC and HDL-C levels are the most important risk factors that explain the higher susceptibility of women compared to men. ${ }^{36}$ Hajian-Tilaki et al. also reported that obesity was significantly higher in females. ${ }^{37}$ According to the results of our study, elevated triglyceride was the second most prevalent component of MetS after obesity. Noshad and colleagues reported the prevalence of elevated triglyceride as $37.39 \%,{ }^{38}$ while Ortiz-Rodriguez reported the prevalence of elevated triglyceride as $77.8 \%$ among 65 year old elderly. ${ }^{39}$ Reducing abdominal obesity to prevent MetS and its consequences should be a priority for prevention programs because reduced abdominal obesity is associated with reduced risk of MetS and adverse cardiovascular consequences.

Results show higher prevalence of MetS with increased age decades, and the frequency of all components of MetS were shown to increase at higher age categories. However, reduced HDL-C decreased, and elevated triglyceride was stable with age. Mokhayeri and colleagues showed increased prevalence of MetS with age in both male and female patients. ${ }^{29}$ Noshad and colleagues also demonstrated that the

Table 4

Prevalence of abnormal components of MetS by demographic characteristics based on IDF definition ( $n=10663$ ).

\begin{tabular}{|c|c|c|c|c|c|c|c|}
\hline Variable & Subgroup & 0 & 1 & 2 & 3 & 4 & 5 \\
\hline \multirow[t]{3}{*}{ Age group (years) } & $40-49$ & $12.74(11.81-13.72)$ & $24.32(23.12-25.57)$ & $29.81(28.51-31.13)$ & $21.83(20.67-23.03)$ & $9.24(8.44-10.10)$ & $2.04(1.67-2.49)$ \\
\hline & $50-59$ & $9.44(8.54-10.42)$ & $20.85(19.58-22.18)$ & $29.52(28.09-31.00)$ & $23.27(21.95-24.65)$ & $12.47(11.45-13.57)$ & $4.41(3.80-5.12)$ \\
\hline & $60-69$ & $6.89(5.91-8.03)$ & $18.53(16.96-20.20)$ & $27.41(25.59-29.30)$ & $26.01(24.22-27.88)$ & $15.96(14.49-17.54)$ & $5.18(4.33-6.18)$ \\
\hline \multirow[t]{2}{*}{ Sex } & Male & $20.34(19.21-21.51)$ & $29.43(28.15-30.75)$ & $26.95(25.70-28.23)$ & $15.68(14.67-16.74)$ & $6.31(5.65-7.04)$ & $1.27(0.98-1.63)$ \\
\hline & Female & $2.43(2.07-2.86)$ & $15.91(15.00-16.86)$ & $31.00(29.84-32.19)$ & $29.18(28.04-30.35)$ & $16.11(15.20-17.07)$ & $5.33(4.78-5.93)$ \\
\hline \multirow[t]{2}{*}{ Place of residence } & Urban & $8.67(7.87-9.45)$ & $20.78(19.61-22.01)$ & $30.54(29.20-31.92)$ & $23.91(22.67-25.19)$ & $12.77(11.81-13.78)$ & $3.30(2.81-3.87)$ \\
\hline & Rural & $11.55(10.78-12.37)$ & $22.68(21.66-23.73)$ & $28.26(27.16-29.39)$ & $22.71(21.69-23.77)$ & $11.07(10.32-11.88)$ & $3.69(3.25-4.19)$ \\
\hline \multirow[t]{2}{*}{ Marital status } & Single & $3.07(2.22-4.23)$ & $14.43(12.53-16.56)$ & $26.64(24.18-29.25)$ & $29.46(26.91-32.14)$ & $19.29(17.13-21.66)$ & $7.08(5.75-8.70)$ \\
\hline & Married & $11.26(10.64-11.91)$ & $22.81(21.98-23.67)$ & $29.53(28.62-30.45)$ & $22.43(21.61-23.29)$ & $10.85(10.24-11.49)$ & $3.09(2.79-3.46)$ \\
\hline \multirow[t]{2}{*}{ Education } & Illiterate & 8.37(7.67-9.13) & 19.13(18.12-20.18) & $28.65(27.48-29.85)$ & $25.00(23.88-26.15)$ & $13.94(13.05-14.87)$ & $4.88(4.35-5.48)$ \\
\hline & Literate & $12.54(11.66-13.48)$ & $24.94(23.76-26.15)$ & $29.82(28.58-31.10)$ & $21.23(20.13-22.38)$ & $9.39(8.62-10.23)$ & $2.04(1.69-2.47)$ \\
\hline \multirow[t]{2}{*}{ Job } & Unemployed & $3.65(3.17-4.20)$ & $15.67(14.71-16.69)$ & $29.39(28.16-30.65)$ & $28.91(27.68-30.16)$ & $16.63(15.63-17.67)$ & $5.73(5.12-6.40)$ \\
\hline & Employed & $16.62(15.66-17.63)$ & $27.70(26.53-28.89)$ & $29.04(27.85-30.25)$ & $17.89(16.90-18.92)$ & $7.52(6.59-7.96)$ & $1.48(1.19-1.84)$ \\
\hline Total & & $10.36(9.79-10.95)$ & $21.89(21.12-22.69)$ & $29.21(28.35-30.08)$ & $23.21(22.41-24.02)$ & $11.77(11.18-12.40)$ & $3.53(3.20-3.90)$ \\
\hline
\end{tabular}


prevalence of MetS and all its components were significant in all fiveyear age groups, except reduced HDL-C, ${ }^{38}$ which was consistent with our study. The Isfahan healthy heart program study in Iran revealed the prevalence of MetS as $49.7 \%$ and $17.5 \%$ in subjects aged 60 years and older, and 60 years and younger, respectively. ${ }^{40}$ Kuzuya and colleagues showed increased frequency of MetS and its components with age, and reported the highest prevalence of MetS in 60-69 age category. ${ }^{41} \mathrm{Al}-$ though older age is associated with development of more frequent risk factors, our results showed that older age may affect the prevalence of MetS regardless of genetic and environmental changes ${ }^{42}$ therefore, we suggest that training intervention aimed at prevention and reduction of MetS must focus on elderly. ${ }^{43}$

The prevalence of MetS was shown to be two times higher in females $(50.2 \%)$ than males. Also, all components of MetS were more prevalent amongst female subjects. Hattori and colleagues conducted a study on japenesse people, and reported that the prevalence of MetS was significantly higher in male subjects $(23.3 \%)$ than female subjects $(8.7 \%) .{ }^{44}$ Ebrahimi et al. reported the prevalence of MetS as $10.88 \%$ among males and $13.03 \%$ among females. ${ }^{45}$ Hajian-Tilaki and colleagues also reported the overall prevalence of MetS as $42.3 \%$ (36.5\% in males vs. $47.1 \%$ in females). ${ }^{17}$ Mokhayeri and colleagues reported the prevalence of MetS as $22 \%$ and $33 \%$ among male and female subjects, respectively. ${ }^{29}$ Some studies also proposed that the prevalence of MetS was two times higher in females, ${ }^{35}$ which was in compliance with the present study. the higher prevalence of MetS in our study may be due to higher prevalence of obesity and physical inactivity among women.

The frequency of MetS was higher in illiterate subjects. The prevalence of high blood pressure, abdominal obesity and impaired fasting glucose were significantly higher in illiterate subjects. However, the prevalence of elevated triglyceride and reduced HDL-C were not significantly different. Ross and colleagues proposed that the risk of MetS was $12 \%$ lower in subjects with 9 or higher years of schooling. ${ }^{27} \mathrm{~A}$ number of previous studies also revealed a reverse association between lower educational level and risk of MetS. ${ }^{46,47}$ Ha et al. reported that subjects with high school education or higher were less likely to develop three or four components of MetS compared with those with high school and primary school education. ${ }^{48}$ In contrast, a study conducted on Chinese adults showed that CVD risk factors are more prevalent in high-income families with high educational level. ${ }^{49}$ Accordingly, there is evidence that lower education is correlated with lower income and lower socioeconomic status. ${ }^{46}$ Besides, higher educated individuals tend to have more health information and subsequently have better health status and healthier lifestyle.

The MetS was shown to be more prevalent in subjects living in urban areas compared to rural subjects, but the difference was not significant. Cozma and colleagues stated that living in rural areas is a major risk factor for MetS. ${ }^{46}$ Noshad and colleagues also showed that MetS and all is individual components were significant by area of living, with more significant difference in subjects living in urban areas, ${ }^{38}$ which was in accordance with results of our study. the mild difference between the results of these two studies may be contributed to urbanization of Iran as well as diet modification in both urban and rural areas, ${ }^{50}$ which significantly affect the frequency of abdominal obesity and subsequently other components of MetS. Moreover, the cultural background and lifestyles of urban subjects is relatively similar to rural subjects in Kharameh County.

About $90 \%$ of the subjects displayed at least one component of MetS ( $80 \%$ in males vs. $97 \%$ in females). Noshad and colleagues reported that $87 \%$ of the subjects had at least one MetS component, and $6 \%$ had all five components. ${ }^{38}$ Fakhrzadeh et al. also revealed that $88 \%$ of adults displayed at least one MetS component. ${ }^{51}$ Thus, identification of MetS at early stages may significantly contribute to prevention of MetS and its progression in the future.

\subsection{Strength and limitations of the study}

Some of the strength of this study were large sample size and that it used data from a population-based study. Besides, data collection was performed using accurate and valid tools and all questionnaires were electronically completed and all study data were recorded online in the cohort study through a dedicated platform, which insured the accuracy of the collected data. since we obtained all data on treatment and patient's medical history, all implications regarding medical conditions and related medications, such as diabetes and hypertension drugs were included in the definitions. Therefore, those studies lacking such information were more likely to report lower prevalence of MetS and related components. The cross-sectional design of the present paper made it difficult to derive causal relationships. Moreover, lack of evaluation of changes in MetS and its components was another limitation of this study.

\section{Conclusion}

The findings of this study indicate high prevalence of metabolic risk factors for CVDs in Fars province. The frequency of all risk factors were shown to be higher in male gender, older people, illiterates, singles, and unemployed individuals. This study with a large sample size would contribute to establishment of efficient interventions and programs aimed at reducing the prevalence of MetS by health staff, supervisors and policymakers. We suggest more accurate assessment of MetS components in other phases of PERSIAN cohort study because assessment of causal relationships requires longitudinal-type studies. According to the results of this study, medication treatment is not the best approach to control MetS, but lifestyle modification, including improvement of lifestyles and provide health training intervention for identified high-risk cases may reduce the prevalence of MetS.

\section{Details of funding source}

My Research Project was fully sponsored by \{Shiraz University of Medical Sciences\} with grant number (97-01-04-19255).

Ethical approval was obtained from the research ethics committee of Shiraz University of Medical sciences (grand no: IR.SUMS.REC.1398.445).

\section{Declaration of competing interest}

No declare.

\section{Acknowledgement}

This paper is part of a thesis conducted by Hossein-Ali Nikbakht, $\mathrm{PhD}$ student of epidemiology, and a research project conducted in Medical University of Shiraz (97-01-04-19255).

\section{Appendix A. Supplementary data}

Supplementary data to this article can be found online at https:// doi.org/10.1016/j.cegh.2020.01.001.

\section{References}

1. Maaten S, Kephart G, Kirkland S, Andreou P. Chronic disease risk factors associated with health service use in the elderly. BMC Health Serv Res. 2008;8:237.

2. O'Neill S, O'Driscoll L. Metabolic syndrome: a closer look at the growing epidemic and its associated pathologies. Obes Rev. 2015;16(1):1-12.

3. Mente A, Yusuf S, Islam S, et al. Metabolic syndrome and risk of acute myocardial infarction a case-control study of 26,903 subjects from 52 countries. J Am Coll Cardiol. 2010;55(21):2390-2398.

4. Sundstrom J, Riserus U, Byberg L, Zethelius B, Lithell H, Lind L. Clinical value of the metabolic syndrome for long term prediction of total and cardiovascular mortality: prospective, population based cohort study. BMJ. 2006;332(7546):878-882. 
5. Beltran-Sanchez H, Harhay MO, Harhay MM, McElligott S. Prevalence and trends of metabolic syndrome in the adult U.S. population, 1999-2010. J Am Coll Cardiol. 2013;62(8):697-703.

6. Alberti KG, Zimmet P, Shaw J. Metabolic syndrome-a new world-wide definition. A consensus statement from the international diabetes federation. Diabet Med. 2006;23(5):469-480.

7. Hajian-Tilaki K. Metabolic syndrome and its associated risk factors in Iranian adults: a systematic review. Caspian J Intern Med. 2015;6(2):51-61.

8. Pan WH, Yeh WT, Weng LC. Epidemiology of metabolic syndrome in Asia. Asia Pac $J$ Clin Nutr. 2008;17(Suppl 1):37-42.

9. Ford ES. Risks for all-cause mortality, cardiovascular disease, and diabetes associated with the metabolic syndrome: a summary of the evidence. Diabetes Care. 2005;28(7):1769-1778

10. Ghaem Maralani H, Tai BC, Wong TY, et al. Metabolic syndrome and mortality in the elderly: a time-dependent association. Diabetes Res Clin Pract. 2013;99(2):209-216.

11. Hwang LC, Bai CH, You SL, Sun CA, Chen CJ. Description and prediction of the development of metabolic syndrome: a longitudinal analysis using a markov model approach. PLoS One. 2013;8(6):e67436.

12. Nakao YM, Miyawaki T, Yasuno S, et al. Intra-abdominal fat area is a predictor for new onset of individual components of metabolic syndrome: MEtabolic syndRome and abdominaL ObesiTy (MERLOT study). Proc Jpn Acad Ser B Phys Biol Sci. 2012;88(8):454-461.

13. Keane D, Kelly S, Healy NP, McArdle MA, Holohan K, Roche HM. Diet and metabolic syndrome: an overview. Curr Vasc Pharmacol. 2013;11(6):842-857.

14. Teixeira TF, Alves RD, Moreira AP, Peluzio Mdo C. Main characteristics of metabolically obese normal weight and metabolically healthy obese phenotypes. Nutr Rev. 2015;73(3):175-190.

15. Alberti KG, Eckel RH, Grundy SM, et al. Harmonizing the metabolic syndrome: a joint interim statement of the international diabetes federation task force on epidemiology and prevention; national heart, lung, and blood institute; American heart association; world heart federation; international atherosclerosis society; and international association for the study of obesity. Circulation. 2009;120(16):1640-1645.

16. Xi B, He D, Hu Y, Zhou D. Prevalence of metabolic syndrome and its influencing factors among the Chinese adults: the China Health and Nutrition Survey in 2009. Prev Med. 2013;57(6):867-871.

17. Hajian-Tilaki K, Heidari B, Firouzjahi A, Bagherzadeh M, Hajian-Tilaki A, Halalkhor S. Prevalence of metabolic syndrome and the association with socio-demographic characteristics and physical activity in urban population of Iranian adults: a population-based study. Diabetes Metab Syndr. 2014;8(3):170-176.

18. Poustchi H, Eghtesad S, Kamangar F, et al. Prospective epidemiological research studies in Iran (the Persian cohort study): rationale, objectives, and design. Am J Epidemiol. 2018;187(4):647-655

19. Azizi F, Hadaegh F, Khalili D, et al. Appropriate definition of metabolic syndrome among Iranian adults: report of the Iranian National Committee of Obesity. Arch Iran Med. 2010;13(5):426-428.

20. Persell SD, Lloyd-Jones DM, Baker DW. Implications of changing national cholesterol education program goals for the treatment and control of hypercholesterolemia. $J$ Gen Intern Med. 2006;21(2):171-176.

21. Mozumdar A, Liguori G. Persistent increase of prevalence of metabolic syndrome among U.S. adults: NHANES III to NHANES 1999-2006. Diabetes Care. 2011;34(1):216-219.

22. Vernay M, Salanave B, de Peretti C, et al. Metabolic syndrome and socioeconomic status in France: the French nutrition and health survey (ENNS, 2006-2007). Int $J$ Public Health. 2013;58(6):855-864.

23. Gundogan K, Bayram F, Capak M, et al. Prevalence of metabolic syndrome in the Mediterranean region of Turkey: evaluation of hypertension, diabetes mellitus, obesity, and dyslipidemia. Metab Syndrome Relat Disord. 2009;7(5):427-434.

24. Salas R, Bibiloni Mdel M, Ramos E, et al. Metabolic syndrome prevalence among Northern Mexican adult population. PLoS One. 2014;9(8):e105581.

25. Chang SH, Chen MC, Chien NH, Wu LYCE. Original research: examining the links between lifestyle factors and metabolic syndrome. Am J Nurs. 2016;116(12):26-36.

26. Moon S. Unhealthy lifestyle behaviors in Korean people with metabolic syndrome. $J$ Community Health Nurs. 2017;34(2):69-79.

27. Roos V, Elmstahl S, Ingelsson E, Sundstrom J, Arnlov J, Lind L. Alterations in multiple lifestyle factors in subjects with the metabolic syndrome independently of obesity. Metab Syndrome Relat Disord. 2017;15(3):118-123.

28. Delavari A, Forouzanfar MH, Alikhani S, Sharifian A, Kelishadi R. First nationwide study of the prevalence of the metabolic syndrome and optimal cutoff points of waist circumference in the Middle East: the national survey of risk factors for noncommunicable diseases of Iran. Diabetes Care. 2009;32(6):1092-1097.

29. Mokhayeri Y, Riahi SM, Rahimzadeh S, Pourhoseingholi MA, Hashemi-Nazari SS. Metabolic syndrome prevalence in the Iranian adult's general population and its trend: a systematic review and meta-analysis of observational studies. Diabetes Metab Syndr. 2018;12(3):441-453.

30. Conti FF, Brito Jde O, Bernardes N, et al. Positive effect of combined exercise training in a model of metabolic syndrome and menopause: autonomic, inflammatory, and oxidative stress evaluations. Am J Physiol Regul Integr Comp Physiol. 2015;309(12):R1532-R1539.

31. Vaidya D, Szklo M, Ding J, et al. Agreement of two metabolic syndrome definitions and their association with subclinical atherosclerosis: multi-ethnic study of atherosclerosis cross sectional study. Metab Syndrome Relat Disord. 2007;5(4):343-352.

32. Kaykhaei M, Hashemi M, Narouie B, et al. Prevalence of metabolic syndrome in adult population from zahedan, southeast Iran. Iran J Public Health. 2012;41(2):70-76.

33. Ryu H, Chin DL. Factors associated with metabolic syndrome among Korean office workers. Arch Environ Occup Health. 2017;72(5):249-257.

34. Mirzazadeh A, Salimzadeh H, Arabi M, Navadeh S, Hajarizadeh B, Haghdoost AA. Trends of obesity in Iranian adults from 1990s to late 2000s; a systematic review and meta-analysis. Middle East journal of digestive diseases. 2013;5(3):151-157.

35. Cuschieri S, Vassallo J, Calleja N, Pace N, Mamo J. The effect of age, gender, TG/ HDL-C ratio and behavioral lifestyles on the metabolic syndrome in the high risk Mediterranean Island population of Malta. Diabetes Metab Syndr. 2017;11(Suppl 1) S321-s7.

36. Sekgala MD, Monyeki KD, Mogale A, et al. The risk of metabolic syndrome as a result of lifestyle among Ellisras rural young adults. J Hum Hypertens. 2018;32(89):572-584.

37. Hajian-Tilaki K, Heidari B, Firouzjahi AR. Clustering of cardio metabolic risk factors in Iranian adult population: a growing problem in the north of Iran. Diabetes Metab Syndr. 2017;11(Suppl 1) S277-s81.

38. Noshad S, Abbasi M, Etemad K, et al. Prevalence of metabolic syndrome in Iran: a 2011 update. J Diabetes. 2017;9(5):518-525.

39. Ortiz-Rodriguez MA, Yanez-Velasco L, Carnevale A, et al. Prevalence of metabolic syndrome among elderly Mexicans. Arch Gerontol Geriatr. 2017:73:288-293.

40. Sarrafzadegan N, Gharipour M, Sadeghi M, Khosravi AR, Tavassoli AA. Metabolic syndrome in Iranian elderly. ARYA atherosclerosis. 2012;7(4):157-161.

41. Kuzuya M, Ando F, Iguchi A, Shimokata H. Age-specific change of prevalence of metabolic syndrome: longitudinal observation of large Japanese cohort. Atherosclerosis. 2007;191(2):305-312.

42. Khosravi-Boroujeni H, Sarrafzadegan N, Sadeghi M, et al. Secular trend of metabolic syndrome and its components in a cohort of Iranian adults from 2001 to 2013. Metab Syndrome Relat Disord. 2017;15(3):137-144.

43. Ghaem Maralani H, Tai BC, Wong TY, et al. The prognostic role of body mass index on mortality amongst the middle-aged and elderly: a competing risk analysis. Diabetes Res Clin Pract. 2014;103(1):42-50.

44. Hattori T, Konno S, Munakata M. Gender differences in lifestyle factors associated with metabolic syndrome and preliminary metabolic syndrome in the general population: the watari study. Intern Med. 2017;56(17):2253-2259.

45. Ebrahimi H, Emamian MH, Shariati M, Hashemi H, Fotouhi A. Metabolic syndrome and its risk factors among middle aged population of Iran, a population based study. Diabetes Metab Syndr. 2016;10(1):19-22.

46. Cozma A, Sitar-Taut A, Urian L, et al. Unhealthy lifestyle and the risk of metabolic syndrome-the Romanian experience. Journal of Mind and Medical Sciences. 2018;5(2):218-229.

47. Kazaz I, Angin E, Kabaran S, Iyigun G, Kirmizigil B, Malkoc M. Evaluation of the physical activity level, nutrition quality, and depression in patients with metabolic syndrome: comparative study. Medicine (Baltim). 2018;97(18):e0485.

48. Ha S, Choi HR, Lee YH. Clustering of four major lifestyle risk factors among Korean adults with metabolic syndrome. PLoS One. 2017;12(3):e0174567.

49. Xu S, Jiayong Z, Li B, et al. Prevalence and clustering of cardiovascular disease risk factors among Tibetan adults in China: a population-based study. PLoS One. 2015;10(6):e0129966.

50. Ghasemian A, Ataie-Jafari A, Khatibzadeh S, et al. National and sub-national burden of chronic diseases attributable to lifestyle risk factors in Iran 1990 - 2013; study protocol. Arch Iran Med. 2014;17(3):146-158.

51. Fakhrzadeh H, Ebrahimpour P, Pourebrahim R, Heshmat R, Larijani B. Metabolic syndrome and its associated risk factors in healthy adults: a population-based study in Iran. Metab Syndrome Relat Disord. 2006;4(1):28-34. 